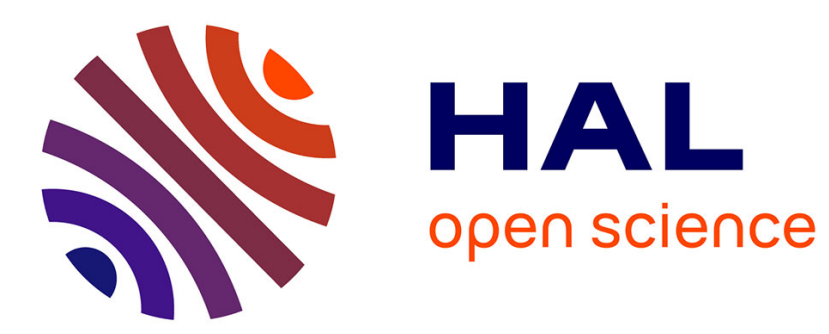

\title{
Dielectric properties in microwave remote plasma sustained in argon: expanding plasma conditions
}

Jean-Louis Jauberteau, Isabelle Jauberteau

\section{To cite this version:}

Jean-Louis Jauberteau, Isabelle Jauberteau. Dielectric properties in microwave remote plasma sustained in argon: expanding plasma conditions. Physics of Plasmas, 2012, 19 (11), pp.110701. 10.1063/1.4766897. hal-00771761

\section{HAL Id: hal-00771761 https://hal.science/hal-00771761}

Submitted on 5 Apr 2017

HAL is a multi-disciplinary open access archive for the deposit and dissemination of scientific research documents, whether they are published or not. The documents may come from teaching and research institutions in France or abroad, or from public or private research centers.
L'archive ouverte pluridisciplinaire HAL, est destinée au dépôt et à la diffusion de documents scientifiques de niveau recherche, publiés ou non, émanant des établissements d'enseignement et de recherche français ou étrangers, des laboratoires publics ou privés. 
Dielectric properties in microwave remote plasma sustained in argon: Expanding plasma conditions

J. L. Jauberteau and I. Jauberteau

Citation: Physics of Plasmas 19, 110701 (2012); doi: 10.1063/1.4766897

View online: http://dx.doi.org/10.1063/1.4766897

View Table of Contents: http://aip.scitation.org/toc/php/19/11

Published by the American Institute of Physics

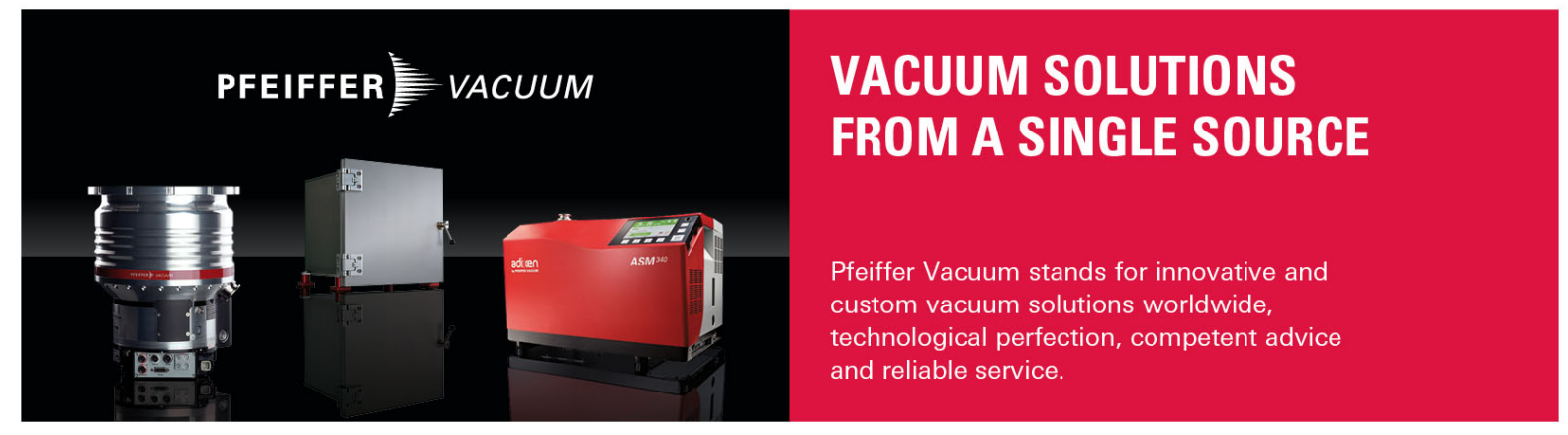




\title{
Dielectric properties in microwave remote plasma sustained in argon: Expanding plasma conditions
}

\author{
J. L. Jauberteau ${ }^{a)}$ and I. Jauberteau \\ UMR 7315 CNRS, SPCTS, 12 rue Atlantis, 87068 Limoges, France
}

(Received 17 July 2012; accepted 26 October 2012; published online 8 November 2012)

\begin{abstract}
This work is devoted to the study of the relative permittivity in argon expanding plasma produced below a microwave discharge sustained in a quartz tube and working at $2.45 \mathrm{GHz}$. We discuss results and explain the microwave propagation within the reactor, outside the quartz tube. It is shown that at low pressures $(133 \mathrm{~Pa})$ and at powers ranging from $100 \mathrm{~W}$ to $400 \mathrm{~W}$, the wave frequency remains lower than the plasma frequency anywhere in the expanding plasma. Under these conditions, the real part of the relative permittivity is negative and the wave is reflected. Surprisingly, in these conditions, the plasma is produced inside and outside the quartz tube, below the wave launcher. This effect can be explained considering a surface wave propagating at the surface of the quartz tube then into the reactor, on the external surface of the expanding plasma below the quartz tube. (C) 2012 American Institute of Physics. [http://dx.doi.org/10.1063/1.4766897]
\end{abstract}

Microwave plasma, working at $2.45 \mathrm{GHz}$ is used for various industrial applications like surface treatments, ${ }^{1,2}$ microcircuit fabrications for electronic devices, ${ }^{3}$ or chemical transformations. ${ }^{4-6}$ These plasma discharges are sustained in electrode-less reactor. However, in an unmagnetized plasma, the electromagnetic wave can propagate only at low electron density and it is reflected as soon as the wave frequency becomes lower than the plasma frequency. ${ }^{7}$ At $2.45 \mathrm{GHz}$, the critical electron density for the wave propagation is $1.89 \times 10^{15} \mathrm{~m}^{-3}$. The surface wave plasma produced by means of a microwave discharge is a promising alternative solution to maintain a large electron density in electrode-less discharges. ${ }^{8}$ In the present work, we study the dielectric properties in different parts of a microwave remote plasma and we discuss the plasma expansion conditions within the reactor. The way of the wave propagation below the wave launcher within the reactor, producing an expanding plasma plume in the vacuum, has been highlighted for the first time. It explains the different electron heating modes observed in such device according to the electron density.

Figure 1 shows the experimental setup. A microwave discharge working at $2.45 \mathrm{GHz}$ is sustained in argon at low pressure $(133 \mathrm{~Pa})$ by means of a SAIREM GMP 12KE generator. The wave launcher (SAIREM $\mathrm{m}=0$ mode surfacewave launcher, length $60 \mathrm{~cm}$ and width $9 \mathrm{~cm}$ ) is fixed above a stainless steel cylindrical reactor (diameter $11 \mathrm{~cm}$, length $25 \mathrm{~cm}$ ) used for the plasma expansion. Argon is injected within a quartz tube (inner diameter $20 \mathrm{~mm}$, external $24 \mathrm{~mm}$ ) crossing the wave launcher and open in the reactor, few centimeters below the end of the wave launcher. The pressure is maintained constant by means of a Roots blower pump and the gas drift velocity within the quartz tube is estimated equal to $20 \mathrm{~m} / \mathrm{s}$, by means of mass flow meter. The plasma diagnostic is performed by means of a cylindrical Langmuir probe moving along the quartz tube axis below the tube exit. The probe tip is a tungsten wire (diameter $0.1 \mathrm{~mm}$ and length

\footnotetext{
a)e-mail: jean-louis.jauberteau@unilim.fr.
}

$5 \mathrm{~mm}$ ). It is small enough so that it does not disturb the plasma. The current $I_{p}$ collected by the probe tip biased at a negative potential $\left(-\mathrm{Va}+\mathrm{RI}_{\mathrm{P}}\right.$ ) is measured through a $5 \mathrm{~K} \Omega$ resistor placed in the electrical circuit, by means of a DAS 1600 Keithley data acquisition board. Each value recorded is averaged over 50 data acquisitions performed at a $10 \mathrm{KHz}$ sampling frequency. Electron energy distribution function (EEDF) is deduced from these I-V probe characteristics using the Druyvesteyn theory

$$
f\left(\varepsilon_{e}=-e V\right)=\frac{2}{A_{\mathrm{P}} e^{2}} \sqrt{\frac{2 m_{e} V}{e}} \frac{d^{2} I_{P}}{d V^{2}},
$$

where $A_{\mathrm{p}}$ is the probe area, $\varepsilon_{\mathrm{e}}$ is the kinetic electron energy, $I_{\mathrm{p}}$ is the probe current collected, and $V$ is the probe voltage. It is referred to the plasma potential, which corresponds to the zero crossing point of the second derivative curve on the $\mathrm{V}$ axis. The other symbols have their usual meaning. The second derivative of the $\mathrm{I}-\mathrm{V}$ probe characteristic is measured using the numerical method already detailed in previous articles. ${ }^{9,10}$ The electron density $\left(\mathrm{n}_{\mathrm{e}}\right)$ and the mean energy $\left(\left\langle\varepsilon_{\mathrm{e}}\right\rangle\right)$ are calculated by integrating over the EEDF

$$
n_{e}=\int_{0}^{\infty} f\left(\varepsilon_{e}\right) d \varepsilon_{e}
$$

and

$$
\left\langle\varepsilon_{e}\right\rangle=\frac{1}{n_{e}} \int_{0}^{\infty} \varepsilon_{e} f\left(\varepsilon_{e}\right) d \varepsilon_{e} .
$$

It as been shown ${ }^{11}$ that the EEDF measured within the expanding plasma is not a Maxwell-Boltzmann distribution, the mean electron energy is low and ranges from $0.3 \mathrm{eV}$ to $0.6 \mathrm{eV}$ and the electron density is large and ranges from $1 \times 10^{16} \mathrm{~m}^{-3}$ to $3 \times 10^{16} \mathrm{~m}^{-3}$. In such cold plasma, the gas temperature is low, typically $300 \mathrm{~K}$. 


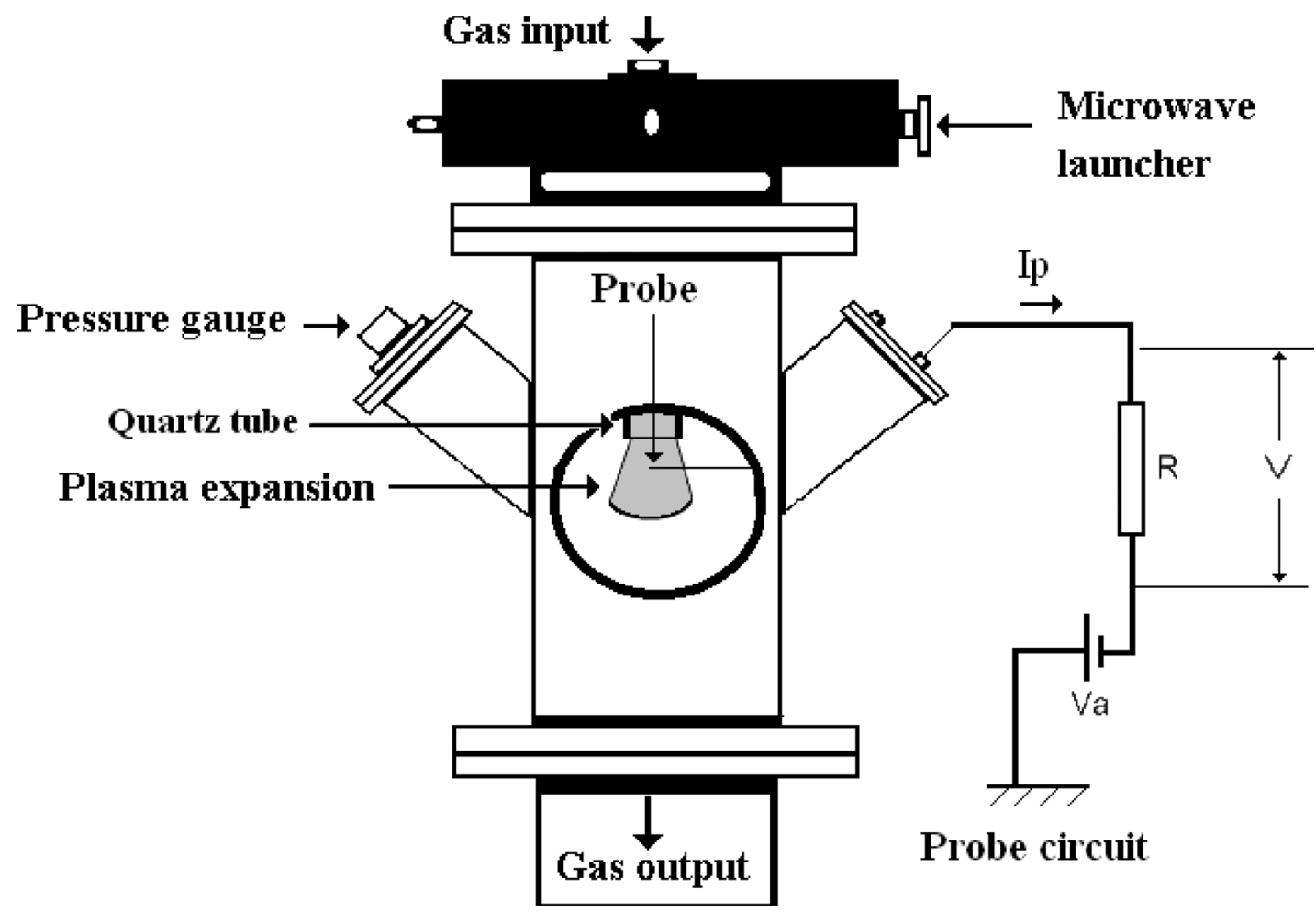

FIG. 1. Experimental setup: The reactor and the probe circuit, $\mathrm{V}$ is the voltage measured through the $5 \mathrm{~K} \Omega$ resistor and Va is the voltage applied to the probe.

The dispersion equation of an electromagnetic wave propagating at $\omega=2 \pi \mathrm{f}$ in a homogeneous unmagnetized plasma is given by $^{7}$

$$
\omega^{2}=\omega_{p}^{2}+c^{2} k^{2}
$$

where $\omega_{\mathrm{p}}, \mathrm{c}$, and $\mathrm{k}$ are the plasma frequency, the light velocity in vacuum, and the wave number $\mathrm{k}=2 \pi / \lambda$, respectively. From this equation, it can be seen that the wave is propagating into the plasma only for $\omega>\omega_{\mathrm{p}}$, i.e., when the electron density is lower than the critical value

$$
n_{e c}=\frac{m_{e} \varepsilon_{0} \omega^{2}}{e^{2}} .
$$

Figure 2 displays the plasma frequency spatially resolved and calculated using the plasma parameters deduced from EEDF curves. This parameter is related to the square root of the electron density. Measurements are performed versus position below the tube discharge exit and for different incident powers between $100 \mathrm{~W}$ and $400 \mathrm{~W}$. In these experiments, incident powers and absorbed powers are equal, because reflected powers are low ( $<5 \%$ incident power). The plasma frequency ranges from $3 \mathrm{GHz}$ to $8 \mathrm{GHz}$. It remains larger than the incident wave frequency $(2.45 \mathrm{GHz})$ anywhere in the expanding plasma where measurements are performed. Under these conditions, the wave cannot propagate into the plasma expanding below the quartz tube exit. Figure 2 also displays the mean electron energy. For convenience, these values reported are in the graph multiplied by 4 . The mean electron energy is low and remains nearly constant whatever the position on the plasma axis is.

It must be notified that because of technical problems due to the data acquisition system, points corresponding to
$100 \mathrm{~W}$ at $3.5 \mathrm{~cm}, 300 \mathrm{~W}$ at $2 \mathrm{~cm}$, and $400 \mathrm{~W}$ at $3 \mathrm{~cm}$ are missing in Figure 2. All the values displayed on the figures have been recorded in the same experiment, i.e., with the same gas flow, the same pressure, and in the same plasma expansion. New experiments performed to add these points on the curves would have introduced new errors on these values due to the changes of some parameters.

The plasma permittivity depends on the electron density and on the collision frequency $(\nu)$ of electrons with the background of heavy particles. It is given by the complex form: ${ }^{7,12}$

$$
\begin{aligned}
\varepsilon_{r} & =\varepsilon_{1}+j \varepsilon_{2}=1-\frac{\omega_{p}^{2}}{\omega(\omega-j \nu)} \\
& =\left(1-\frac{\omega_{p}^{2}}{\left(\omega^{2}+\nu^{2}\right)}\right)-j\left(\frac{\omega_{p}^{2}}{\left(\omega^{2}+\nu^{2}\right)} \frac{\nu}{\omega}\right) .
\end{aligned}
$$

In this plasma, the degree of ionization is low (about $10^{-6}$ ) and electron collisions with heavy particles are mainly electron-neutral collisions $\left(\nu=\nu_{\mathrm{e}-\mathrm{N}}\right)$. In pure argon, the electron-neutral collision cross section $(\sigma)$ (measured using the Townsend method) ranges from $0.15 \times 10^{-20} \mathrm{~m}^{2}$ to $0.25 \times 10^{-20} \mathrm{~m}^{2}$ for electron energy ranging from $0.3 \mathrm{eV}$ to $0.6 \mathrm{eV} .{ }^{15}$ Considering the kinetic theory of perfect gas, the electron-neutral collision frequency can be calculated using the equation $\nu_{e-N}=4 \sigma n v_{e}$, where $\mathrm{v}_{\mathrm{e}}$ is the means electron velocity and $n$ is the neutral concentration at $300 \mathrm{~K}$. It ranges from $70 \mathrm{MHz}$ to $80 \mathrm{MHz}$. It can be seen that this value is much larger than the electron-ion collision frequency determined in the case of Coulomb interaction, ${ }^{13,14}$ which ranges from $1 \mathrm{MHz}$ to $5 \mathrm{MHz}$ in same experimental conditions.

The complex permittivity, calculated using Eq. (6), with plasma parameters $\left(\mathrm{n}_{\mathrm{e}}\right.$ and $\left.<\varepsilon_{\mathrm{e}}>\right)$ measured by means of the 


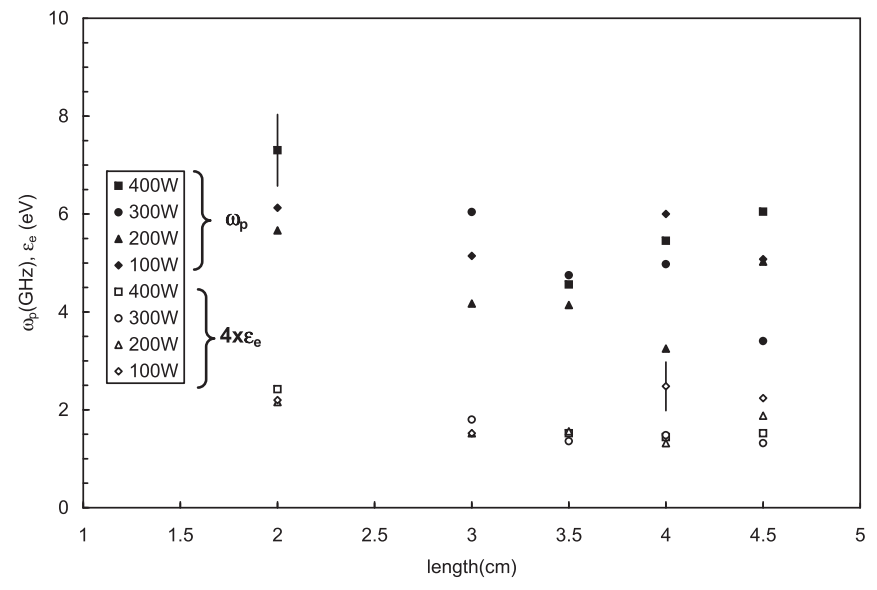

FIG. 2. Plasma frequency (full symbols) and mean electron energy (empty symbols) versus position in the expanding plasma (distance from the quartz tube exit). Measurements are performed at different microwave powers. For the sake of clarity, mean electron energy values are multiplied by 4 .

Langmuir probe is given in Figure 3. The figure displays the change of the real and imaginary parts of the dielectric constant versus wave frequency. The calculations are performed at $400 \mathrm{~W}, 2 \mathrm{~cm}$ below the tube discharge exit. The electron density and the mean energy are equal to $1.68 \times 10^{16} \mathrm{~m}^{-3}$ and $0.6 \mathrm{eV}$, respectively. Under these conditions, the plasma frequency is equal to $7.3 \mathrm{GHz}$. The real part of the dielectric constant increases with increasing $\omega$. It remains below the asymptotic value $\varepsilon_{1}=1$. Two parts are displayed in the figure: At wave frequency lower than the plasma frequency $\left(\omega_{\mathrm{p}}=7.3 \mathrm{GHz}\right)$, the real part of the permittivity is negative and the wave is reflected, at wave frequency larger than 7.3 $\mathrm{GHz}, \varepsilon_{1}$ ranges from 0 to 1 and the wave is partly absorbed. The imaginary part $\varepsilon_{2}$ is positive and it decreases with increasing $\omega$. When $\varepsilon_{2}=0$, the electromagnetic wave is propagating without absorption and $\varepsilon_{1}=1$. These results confirm that the wave propagation in the plasma cannot occur in these conditions, the electron density must be lower than the critical value $\left(\mathrm{n}_{\mathrm{ec}}\right)$.

It is worth noting that under the different experimental conditions discussed in this work, the collision frequency is

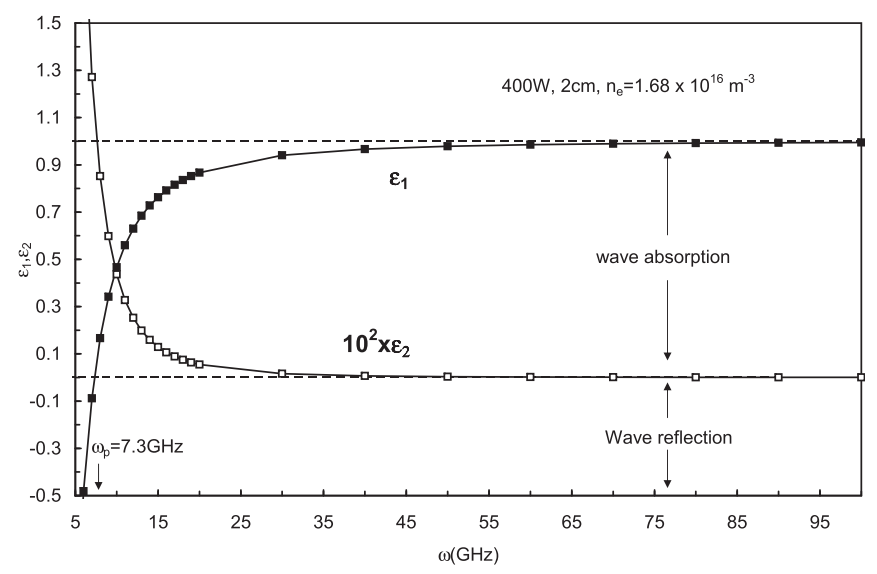

FIG. 3. Real and imaginary parts of the relative permittivity versus microwave frequency; calculations are performed in the case of a microwave power equal to $400 \mathrm{~W}, 2 \mathrm{~cm}$ below the quartz tube exit. The electron density is $1.68 \times 10^{16} \mathrm{~m}^{-3}$ and the mean electron energy is $0.6 \mathrm{eV}$. much lower than the wave frequency $(2.45 \mathrm{GHz})$ and the real and imaginary parts of the permittivity can be approximated using $\varepsilon_{1}=1-\frac{\omega_{p}^{2}}{\omega^{2}}$ and $\varepsilon_{2}=\frac{\omega_{p}^{2} \nu_{e-N}}{\omega^{3}}$, respectively.

It is known ${ }^{1,2,12}$ that in the case of large electron densities, the plasma produced in the quartz tube of this device results in the propagation of a TM surface-wave at the surface of the tube. At the Brewster angle, the transmission of the TM mode across the dielectric interface is total (no reflection). Assuming a bounded plasma, with a semi infinite dielectric $\varepsilon_{\mathrm{b}}$ (quartz tube) and a semi infinite plasma $\varepsilon_{\mathrm{a}}$, the dispersion equation is obtained writing the continuity equation at the interface quartz-plasma for the normal $\left(\mathrm{k}_{\mathrm{za}}, \mathrm{k}_{\mathrm{zb}}\right)$ and tangential $\left(\mathrm{k}_{\mathrm{xa}}, \mathrm{k}_{\mathrm{xb}}\right)$ components in the case of the transmitted and incident wave. ${ }^{8}$ This gives

$$
\begin{aligned}
& k_{x a}=k_{x b}=k_{x}, \\
& \frac{k_{z a}}{\varepsilon_{a}}+\frac{k_{z b}}{\varepsilon_{b}}=0,
\end{aligned}
$$

$k_{x i}^{2}+k_{z i}^{2}=k_{i}^{2}=\varepsilon_{i} \frac{\omega^{2}}{c^{2}}, \mathrm{i}$ is used for dielectrics a or $\mathrm{b}$.

Resolving this system, the tangential component $\mathrm{k}_{\mathrm{x}}$ at the interface is given by

$$
k_{x}^{2}=\frac{\omega^{2}}{c^{2}}\left(\frac{\varepsilon_{a} \varepsilon_{b}}{\varepsilon_{a}+\varepsilon_{b}}\right) .
$$

Assuming that $\varepsilon_{a}=1-\frac{\omega_{p}^{2}}{\omega^{2}}$, the wave propagation at the interface is obtained if $k_{x}^{2}$ is positive, i.e., $\omega_{\mathrm{p}}{ }^{2}>\omega^{2}\left(\varepsilon_{\mathrm{b}}+1\right){ }^{8}$ The tangential component propagates at the interface only when $\mathrm{n}_{\mathrm{e}}>n_{e c}=\omega^{2}\left(\varepsilon_{b}+1\right) \frac{\varepsilon_{0} m_{e}}{e^{2}}$. According to Eq. (9), it can be seen that when $\varepsilon_{\mathrm{a}}$ is negative and when there is a solution for Eq. (10) $\left(\mathrm{k}_{\mathrm{x}}{ }^{2}>0\right)$, the transmitted wave cannot propagate in the normal direction (no solution with $\mathrm{k}_{\mathrm{z}}^{2}>0$ ), the wave propagates only along the tangent at the interface between plasma (a) and dielectric (b). For incident angle different from the Brewster angle, a part of the wave is reflected and the wave is not a pure surface wave but a hybrid wave. ${ }^{8}$

In the present case, with $\omega=2.45 \mathrm{GHz}$ and $\varepsilon_{\mathrm{b}}=3.9$ (for the quartz), $\mathrm{n}_{\mathrm{ec}}=3.6 \times 10^{17} \mathrm{~m}^{-3}$. The critical value $\mathrm{n}_{\mathrm{ec}}$ calculated is larger than the values measured in the plasma expansion outside the quartz tube. Nevertheless, two points must be noted.

First outside the quartz tube the plasma expands in a volume with a larger diameter than the quartz tube diameter, so the electron density is lower than the density inside the quartz tube. Second, the condition $n_{e}>n_{e c}$ is necessary at the interface between the plasma and the quartz and not at the center of the tube. The real part of the dielectric constant is negative inside the tube and the wave cannot propagate until the tube center. So, the electron density is probably larger on the quartz tube wall where electrons are produced than at the center of the quartz tube.

For incident power lower than $80 \mathrm{~W}$, the plasma is confined in the quartz tube then it expands outside the tube with increasing power producing a plasma plume below the tube exit, which length increases with incident power increasing. 
Figure 4 shows the real and imaginary parts of the relative permittivity versus plasma frequency in the case of a $2.45 \mathrm{GHz}$ incident wave frequency and considering the electron energy equal to $0.38 \mathrm{eV}$, which is the mean value measured in the expansion for powers range from 100 to $400 \mathrm{~W}$. Comparing results with plasma frequency measured in the expansion and given in Figure 2, it can be seen that the real part of the permittivity is negative anywhere in the expanding plasma, where probe measurements are performed. Moreover, the plasma expansion outside the quartz tube cannot be due to the plasma diffusion, because the expansion cone is few centimeters long and the mean free path for electron-neutral collisions is ranges from $4 \mathrm{~mm}$ to $5 \mathrm{~mm}$, according to the mean electron energy value. In these conditions, electrons quickly recombine below the quartz tube exit if only diffusion effect is efficient. According to Moisan et al., ${ }^{12}$ a clear and simple way to identify surface-wave discharges is to increase the high frequency (HF) power delivered to the field applicator sustaining the plasma and to check (i) that the plasma column extends beyond this applicator and (ii) that the column length increases accordingly. This is precisely what happened in the present case. To explain the plasma expansion in this part of the reactor, we consider the same dispersion equations at the end of the quartz tube than previously in the quartz tube. So, the wave propagation conditions, for tangential and normal components are also given by Eqs. (7)-(10), assuming a semi-infinite plasma consisting of a dielectric $\varepsilon_{a}=1-\frac{\omega_{p}^{2}}{\omega^{2}}$ on one side and (in a first approximation) a semi-infinite dielectric with a dielectric constant equal to 1 (vacuum permittivity) on the other side. We consider that no plasma is formed outside the cone edge of the expanding plasma below the quartz tube.

Thus, as previously within the quartz tube, the electromagnetic wave which is reflected on the too high density plasma produced below the quartz tube exit can propagate along the interface between the two dielectrics (plasma and vacuum). Considering the Brewster angle, a pure surface wave is obtained if $k_{x}^{2}>0$, i.e., if $\omega_{p}>\omega \sqrt{2}=3.46 \mathrm{GHz}$. This is the case anywhere in the plasma expansion.

To conclude, the plasma expansion below the quartz tube (remote plasma) is probably due to a surface-wave

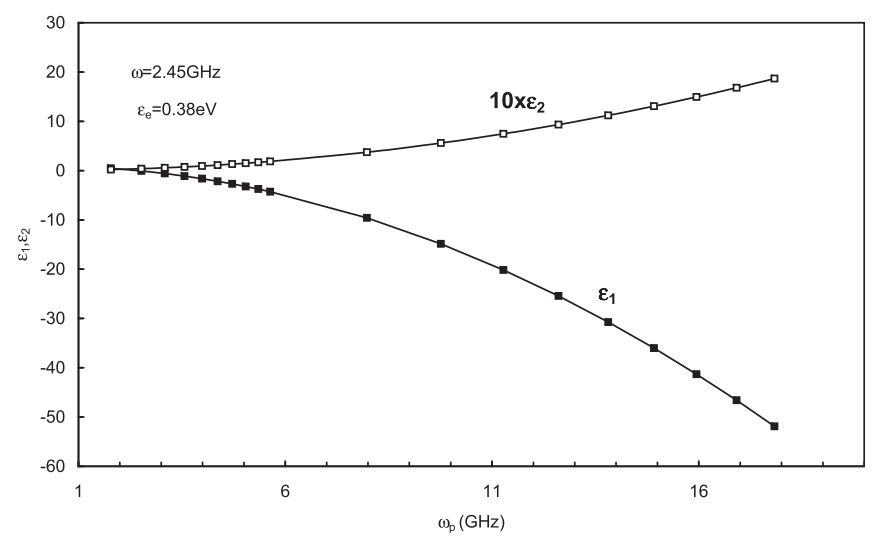

FIG. 4. Real and imaginary parts of the relative permittivity versus plasma frequency within the plasma expansion. The incident wave frequency is 2.45 $\mathrm{GHz}$ and the electron energy is $0.38 \mathrm{eV}$, corresponding to the mean electron energy value measured in the plasma expansion. propagating at the limit between the vacuum and the expanding plasma. In this case, charged species produced on the expanding plasma edge, move from the side to the center of the plasma expansion probably because of diffusion and/or because of local radial electric fields. In the previous works, ${ }^{16}$ we show that expanding plasma in the vessel occurs when the electron density is larger than a critical value. We observe an increase of the electron density and a decrease of the electron energy simultaneously to the plasma expansion. Moreover, we have shown ${ }^{17}$ that according to the experimental conditions, the radial distribution of the $\operatorname{Ar}(420 \mathrm{~nm})$ emission line intensity observed by optical emission spectroscopy (after Abel inversion) is maximum on the side of the plasma expansion and minimum at the center. Such results have also been observed by Moisan et al. ${ }^{18}$ in surface-wave excited discharge. This shows an increase of the radial electron density and/or electron energy from the center to the side of the plasma. In more recent works, Sugai et al. ${ }^{19}$ have observed the same effect, in the case of a planar microwave discharge working at low pressure, the electron heating mode change from a bulk heating mode in low density electron plasma to a surface heating mode in large density plasma. The wave propagation way described in the present work could explain the change of electron heating mode observed by Sugai et al.

However, new investigations and model are necessary to study the electron density and energy spatially resolved from the edge to the center of the expanding plasma and to confirm these results and conclusions.

${ }^{1}$ I. Jauberteau, J. L. Jauberteau, M. N. Semeria, A. Larré, J. Piaguet, and J. Aubreton, Surf. Coat. Technol. 116-119, 222-228 (1999).

${ }^{2}$ I. Jauberteau, T. Merle-Mejean, S. Touimi, S. Weber, A. Bessaudou, A. Passelergue, J. L. Jauberteau, and J. Aubreton, Surf. Coat. Technol. 205, S271-S274 (2011)

${ }^{3}$ J. Hao, Y. Li, and H. Ji, Adv. Mater. Res. 295-297, 1747-1750 (2011).

${ }^{4}$ J. Azadmanjiri, G. P. Simon, K. Suzuki, C. Selomulya, and J. D. Cashion, J. Mater. Chem. 22(2), 617-625 (2012).

${ }^{5}$ P. Pohl and P. Jamroz, J. Anal. At. Spectrom. 26(7), 1317-1337 (2011).

${ }^{6}$ M. Mora, M. del Carmen Garcia, C. Jmenez-Sanchidrian, and F. J. Romero-Salguero, Int. J. Hydrogen Energy 35(9), 4111-4122 (2010).

${ }^{7}$ R. Fitzpatrick, Oscillations and Waves, http://farside.ph.utexas.edu/teaching/315/waves/node48.html.

${ }^{8}$ H. Sugai, I. Ghanashev, and M. Nagatsu, Plasma Sources Sci. Technol. 7, 192-205 (1998).

${ }^{9}$ J. L. Jauberteau and I. Jauberteau, Meas. Sci. Technol. 18, 1235-1249 (2007).

${ }^{10}$ J. L. Jauberteau and I. Jauberteau, Rev. Sci. Instrum. 78, 043501 (2007).

${ }^{11}$ J. L. Jauberteau and I. Jauberteau, Plasma Sources Sci. Technol. 17, 015019 (2008)

${ }^{12}$ C. M. Ferreira, M. Moisan, and Z. Zakrzewski, "Plasma technology," in Microwave Excited Plasma, edited by M. Moisan and J. Pelletier (Elsevier, 1992), Vol. 4, pp. 11-49.

${ }^{13}$ R. Fitzpatrick, Introduction to Plasma Physics: A Graduate Level Course, http://farside.ph.utexas.edu/teaching/plasma/plasma.html.

${ }^{14}$ M. Mathuthu, IEEE Trans. Plasma Sci. 34(6), 2554-2560 (2006).

${ }^{15}$ I. P. Shkarofsky, T. W. Johnston, and M. P. Bachynski, The Particle Kinetics of Plasmas (Addison-Wesley, 1966).

${ }^{16}$ J. L. Jauberteau, M. J. Cinelli, I. Jauberteau, and J. Aubreton. J. Phys. D: Appl. Phys. 32, 445-455 (1999).

${ }^{17}$ L. Thomas, J. L. Jauberteau, J. Aubreton, A. Catherinot, A. R. de Souza, and M. J. Cinelli, Appl. Phys. Lett. 64, 2643-2645 (1994).

${ }^{18}$ M. Moisan, R. Pantel, A. Ricard, V. M. M. Glaude, P. Leprince, and W. P. Allis, Rev. Phys. Appl. 15, 1383-1397 (1980).

${ }^{19}$ H. Sugai, I. Ghanashev, and K. Mizuno, Appl. Phys. Lett. 77, 3523-3525 (2000) 